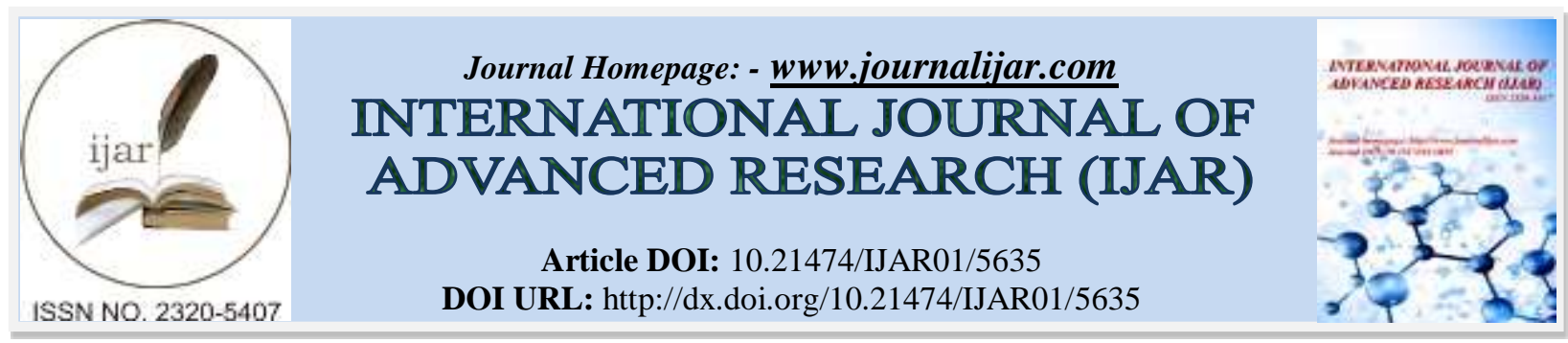

RESEARCH ARTICLE

\title{
OBSTRUCTIVE JAUNDICE- INDUCED SINUS BRADYCARDIA IN CHILD WITH SICKLE CELL DISEASE.
}

\author{
Housam Y. Almadani, Shahad A. Alansari and Banan I. Alsaied. \\ Hematology/ Oncology department, King Fahd Armed Forces Hospital, Jeddah, Kingdom of Saudi Arabia.
}

\section{Manuscript Info}

Manuscript History

Received: 16 August 2017

Final Accepted: 18 September 2017

Published: October 2017

\begin{abstract}
Sinus bradycardia is a rare condition in healthy children. Different causes of bradycardia in pediatrics listed in literature for more than fifty years ago. Obstructive jaundice has been strongly linked to sinus bradycardia. Multiple studies on animals initiated to discover the possible underling mechanism. collectively, bile acid considers as the key role of obstructive jaundice induced bradycardia but other factors emerged including nitric oxide, endogenous opioids, TNF- $\alpha$ and atrial natriuretic pedtide (ANP). No sufficient data found in the literature about the exact mechanism of bradycardia and cholestasis on human subjects specially pediatrics so, in this paper we report an 11 year old girl who diagnosed with obstructive jaundice and sinus bradycardia.
\end{abstract}

Copy Right, IJAR, 2017,. All rights reserved.

\section{Introduction:-}

Obstructive jaundice or cholestasis in pediatrics consider as uncommon but can be subsequently a critical medical condition in which hepatobiliary function is no longer maintained. It is estimated that cholestatic jaundice occur in about 1 in each 2500 term infants(1). The clinical presentation of jaundice or icterus will not be apparent unless the total serum bilirubin level is greater than $2.5-3.0 \mathrm{mg} / \mathrm{dL}(42-51 \mu \mathrm{mol} / \mathrm{L})$ and the direct/ conjugated hyperbilirubinemia when the level is greater than $1.0 \mathrm{mg} / \mathrm{dL}(1,2)$.

Sinus bradycardia is one of the disorders of sinus node function in which the sinoatrial (SA) node producing physiologically improper rhythm. Sinus Node Dysfunction (SND) is also rare in pediatric population and the clinical presentation and degree of severity is determined by varied factors including age, the presence and severity of coexisting systemic disease but most of the patients are asymptomatic $(3,4)$. Different causes of sinus bradycardia have been mentioned in the literature long time ago including the conditions of jaundice and strongly linked to obstructive jaundice but the published studies never include pediatrics(5-7). First review of SND in pediatrics published in the beginning of nineties in which Kugler et al., mentioned that the obstructive jaundice is a nonsurgical cause of SND including sinus bradycardia(3).

To the best of our knowledge, the literature is lacking the sufficient data or reports of the relation between the obstructive jaundice and sinus bradycardia in pediatrics. Therefore, in this paper we report 11 year old sickler girl who diagnosed with obstructive jaundice and sinus bradycardia.

\section{Case Report:-}

This is the history of 11 year 5 month old girl, known case of sickle cell disease with beta thalassemia trait on folic acid supplement and hydroxyurea who presented with classical picture of obstructive jaundice. She had one week 
history of intermittent abdominal pain in epigastrium and right upper quadrant area with no radiation elsewhere specially post prandial. The pain became persistence increasing in the severity in the last two days and became associated to anorexia, vomiting, jaundice and tea colored urine.

On examination, vital signs were ( Temperature 37C, Pulse 87bpm, Respiratory rate 20bpm, Blood pressure 107/72 $\mathrm{mmHg}$, Pain score 2/10). She was conscious, alert, pale and jaundiced ( sclera, skin and mucous membranes). Abdominal examination showed soft, lax abdomen with mild tenderness over epigastrium and right hypochondrium but no rebound tenderness nor murphy's sign and the liver edge were palpable 3-4 $\mathrm{cm}$ below costal margin.

The investigation were consistence with the history and physical examination which were suggestive of obstructive jaundice. CBC ( WBC 9.9 X10^9, Hgb $9.6 \mathrm{~g} / \mathrm{dL}$, platelets 447 X10^9, Reticulocyte 5.6\%), Liver enzymes ( ALT $652 \mathrm{U} / \mathrm{L}$, AST $448 \mathrm{U} / \mathrm{L}$, ALP $316 \mathrm{U} / \mathrm{L}$, Total serum bilirubin $273 \mu \mathrm{mol} / \mathrm{L}$, conjugated $202 \mu \mathrm{mol} / \mathrm{L}$, GGT $141 \mathrm{U} / \mathrm{L}$ ), Lipase $20 \mathrm{U} / \mathrm{L}$, Amylase $57 \mathrm{U} / \mathrm{L}$, Serology of acute infection and the rest of the investigation including electrolytes and coagulation profile were within normal ranges.

Abdominal ultrasound done in other hospital just one day before the presentation to our hospital showed dilated common bile duct(CBD), intra-hepatic biliary dilatation and gallbladder mud. Repeated abdominal ultrasound showed enlarged liver of $15.5 \mathrm{~cm}$ with no focal lesions, normal CBD and intra-hepatic biliary tract.

She seen by pediatric surgery team, pediatric hematology and pediatric gastroenterology. The impression was resolving obstructive jaundice so, she kept NPO on intravenous hydration Ibuprofen when needed and Tazocine. She was clinically improving regarding her abdominal pain and urine color but she kept having elevated liver enzymes and serum bilirubin. Follow up abdominal ultrasound showed CBD measured $2.7 \mathrm{~cm}$, gallbladder (GB) partially distended with wall thickining, liver measured $14 \mathrm{~cm}$ with increase echogenicity and no obvious intrahepatic biliary duct dilatation. Magnetic resonance cholangiopancreatography (MRCP) done showed cholecystitis and cholelithiasis (Image 1) . so, she prepared for surgery and laparoscopic cholecystectomy done revealed mildly inflamed GB with multiple stones.

During her admission she experienced episode of bradycardia of heart rate reaching 45-50 bpm even when she is asleep with maintaining her other vitals within normal ranges for her age. Surface electrocardiography (ECG) showed sinus bradycardia with no other abnormalities which was reviewed by the cardiology along her echocardiography result and no intervention was required for the time-being and to be followed with cardiology with repeated ECG. Post operatively, she still having bradycardia but less frequent and last liver enzyme were ( ALT $89 \mathrm{U} / \mathrm{L}$, ALP $157 \mathrm{U} / \mathrm{L}$, Total serum bilirubin $58 \mu \mathrm{mol} / \mathrm{L}$, conjugated $18 \mu \mathrm{mol} / \mathrm{L}$, GGT $74 \mathrm{U} / \mathrm{L}$ ). She discharged with good clinical condition with follow up appointments.

\section{Discussion:-}

It is well known that cholestasis is causing varies cardiovascular abnormalities includes sinus bradycardia(8). It's challenging to define bradycardia in pediatrics because it is age dependent, Kugler et al., defines the bradycardia in children based on age and method used to detect the heart rate (Table1)(3).

Different theories tried to explain the mechanism of obstructive jaundice that leads to sinus bradycardia, so extensive researches and in vivo/ vitro experiments have been done(8)8. Bile acid has been strongly suggestive of the predominant factor which induce sinus bradycardia by inhibitory impact on the SA node and that achieved by the direct vagal stimulation $(7,9)$. Some studies supported this theory by clinical experiments on rats and rabbits hearts and recognized that the presence of bile acid in the circulation with high concentration in such concentrations found in obstructive jaundice patients is the key role of the inhibitory action $(8,9)$. Our patient had very high levels of serum bilirubin and that was the only explanation of her sinus bradycardia.

Nitric oxide (NO) is consider as other factor that induces sinus bradycardia in cholestasis 8. It has a paracrineacting effect on vascular smooth muscle cells that regulates the cardiac contractile function $(10,11)$. NO produced in hepatocytes which associated with abnormal mitochondrial function and thus affects the hepatic energy metabolism(12). The production of hepatocytic nitric oxide found to be markedly increased in obstructive jaundice in multiple studies conducted on rats hearts $(12,13)$. Overall, these results suggest a negative regulatory effect of NO on cardiac myocytes in obstructive jaundice $(8,14)$. 
Other studies suggest that endogenous opioids which found to be overproduced in cholestasis have indirect effect on the cardiovascular system by induce bradycardia possibly through vagal stimulation but the exact mechanism still not fully understood $(15,16)$.

Different substances found to be increased in obstructive jaundice and suggested to have possible effect on induce sinus bradycardia like TNF- $\alpha$ and atrial natriuretic pedtide (ANP)(8).

Although different researches identified the condition of obstructive jaundice - induced bradycardia and tried to explain the possible mechanisms, most of these studies conducted on animals. From our point of view the literature still lacking for more information regarding previously mentioned mechanisms on human subjects including pediatric population specially patients with higher risk to develop obstructive jaundice like in sickle cell disease (SCD)(17).

\section{Conclusion:-}

We concluded that obstructive jaundice can induce sinus bradycardia in pediatric. So in any patient with obstructive jaundice, heart rate should be monitored. Sinus bradycardia in patients with higher possibility to develop gallstones like patients with SCD obstructive jaundice must be consider as one of the differential diagnosis.

\section{Disclosure:-}

In this paper, there was no conflict of interest.
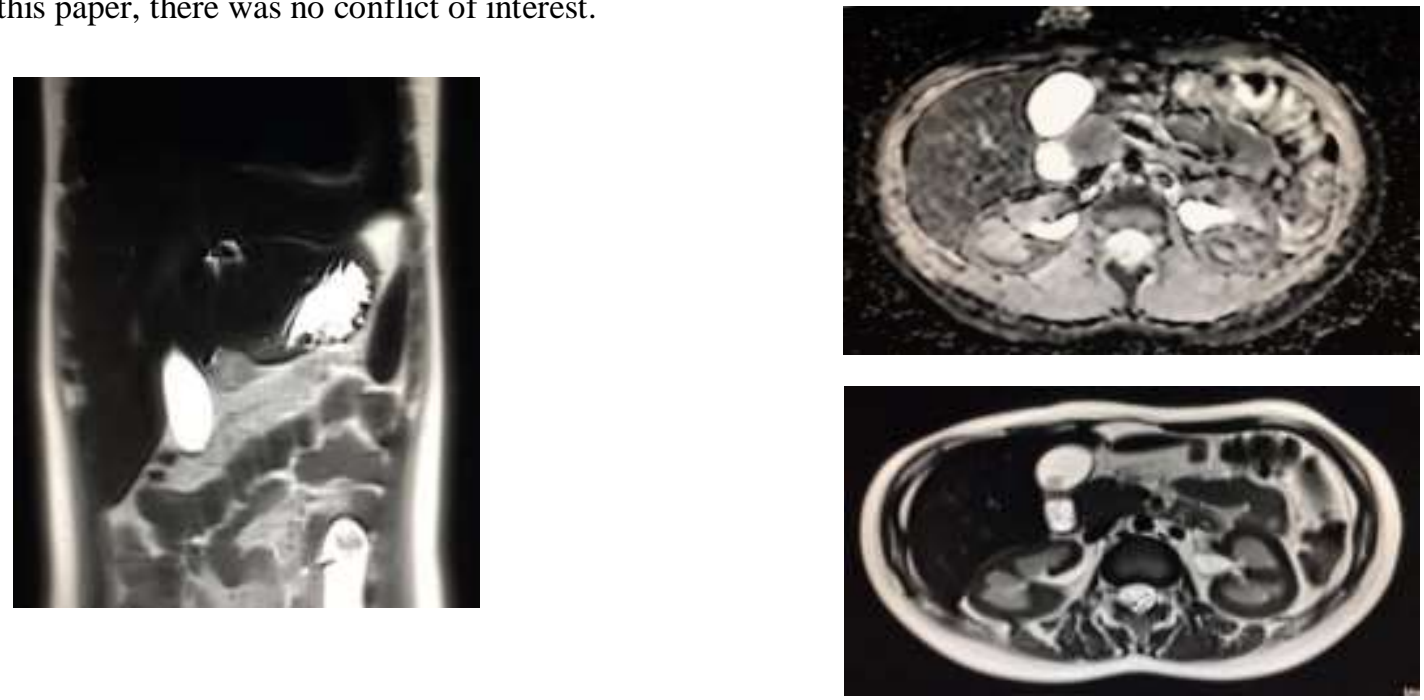

Image 1: MRCP, Mild distended gallbladder, mild thickened wall and multiple intra-luminal filling defect including GB neck. CBD, common hepatic duct (CHD), right hepatic duct (RHD) and lift hepatic duct (LHD) measured $5.5 \mathrm{~mm}, 6 \mathrm{~mm}$, $4.3 \mathrm{~mm}$ and $4.7 \mathrm{~mm}$ respectively with focal narrowing seen at the region of the RHD

\begin{tabular}{|c|c|c|}
\hline Method used & Age & Lower heart rate bpm \\
\hline \multirow[t]{6}{*}{$\begin{array}{l}\text { 24-Hour Ambulatory (Holter) } \\
\text { ECG }\end{array}$} & $<1$ month & $\begin{array}{l}<60 \text { bpm (sleeping) } \\
<80 \text { bpm (awake) }\end{array}$ \\
\hline & 1 month -2 years & $\begin{array}{l}<60 \text { bpm (sleeping) } \\
<80 \mathrm{bpm} \text { ( awake) }\end{array}$ \\
\hline & $2-6$ years & $<60 \mathrm{bpm}$ \\
\hline & $7-11$ years & $<45 \mathrm{bpm}$ \\
\hline & Adolescents and young adults & $<40 \mathrm{bpm}$ \\
\hline & Athletes & $<30 \mathrm{bpm}$ \\
\hline \multirow[t]{2}{*}{ Surface ECG } & Infants and children till 3 years & $<100 \mathrm{bpm}$ \\
\hline & $3-9$ years & $<60 \mathrm{bpm}$ \\
\hline
\end{tabular}




\begin{tabular}{|l|l|l|}
\hline & $9-16$ years & $<50 \mathrm{bpm}$ \\
\hline & $>16$ years & $<40-50 \mathrm{bpm}$ \\
\hline ECG = Electrocardiography, bpm = beat per minute & \\
\hline
\end{tabular}

\section{References:-}

1. Moyer V, Freese DK, Whitington PF, Olson AD, Brewer F, Colletti RB, et al. Guideline for the evaluation of cholestatic jaundice in infants: recommendations of the North American Society for Pediatric Gastroenterology, Hepatology and Nutrition. Journal of pediatric gastroenterology and nutrition. 2004;39(2):115-28.

2. Rosenthal P, Blanckaert N, Kabra PM, Thaler MM. Formation of bilirubin conjugates in human newborns. Pediatric research. 1986;20(10):947-50.

3. Kugler JD. Sinus node dysfunction. Progress in Pediatric Cardiology. 1994;3(4):226-35.

4. Premkumar S, Sundararajan P, Sangaralingam T. Clinical Profile of Cardiac Arrhythmias in Children Attending the Out Patient Department of a Tertiary Paediatric Care Centre in Chennai. Journal of clinical and diagnostic research: JCDR. 2016;10(12):SC06.

5. Kirk JE, Kvorning SA. SINUS BRADYCARDIA A CLZNICAL STUDY OF 515 CONSECUTIVE CASES. Journal of Internal Medicine. 1952;142(S266):625-52.

6. Song E, Segal I, Hodkinson J, Kew M. Sinus bradycardia in obstructive jaundice--correlation with total serum bile acid concentrations. South African medical journal= Suid-Afrikaanse tydskrif vir geneeskunde. 1983;64(14):548-51.

7. Bashour TT, Antonini C, Fisher J. Severe sinus node dysfunction in obstructive jaundice. Annals of internal medicine. 1985;103(3):384-5.

8. Moezi L, Dehpour AR. Cardiovascular abnormalities in obstructive cholestasis: the possible mechanisms. Liver International. 2013;33(1):7-15.

9. Kotake H, Itoh T, Watanabe M, Hisatome I, Hasegawa J, Mashiba H. Effect of bile acid on electrophysiological properties of rabbit sino-atrial node in vitro. British journal of pharmacology. 1989;98(2):357-60.

10. Smith TW, Balligand J-L, Kaye DM, Wiviott SD, Simmons WW, Han X, et al. The role of the NO pathway in the control of cardiac function. Journal of cardiac failure. 1996;2:S141-S7.

11. Seki T, Hagiwara H, Naruse K, Kadowaki M, Kashiwagi M, Demura H, et al. In SituIdentification of Messenger RNA of Endothelial Type Nitric Oxide Synthase in Rat Cardiac Myocytes. Biochemical and biophysical research communications. 1996;218(2):601-5.

12. Tu W, Kitade H, Satoi S, Zhang ZT, Kaibori M, Kwon A-H, et al. Increased nitric oxide production in hepatocytes is involved in liver dysfunction following obstructive jaundice. Journal of Surgical Research. 2002;106(1):31-6.

13. Mani AR, Nahavandi A, Moosavi M, Safarinejad R, Dehpour AR. Dual nitric oxide mechanisms of cholestasisinduced bradycardia in the rat. Clinical and experimental pharmacology and physiology. 2002;29(10):905-8.

14. Nahavandi A, Dehpour AR, Mani AR, Homayounfar H, Abdoli A, Abdolhoseini MR. The role of nitric oxide in bradycardia of rats with obstructive cholestasis. European journal of pharmacology. 2001;411(1):135-41.

15. Gaskari SA, Mani AR, Ejtemaei-Mehr S, Namiranian K, Homayoun H, Ahmadi H, et al. Do endogenous opioids contribute to the bradycardia of rats with obstructive cholestasis? Fundamental \& clinical pharmacology. 2002;16(4):273-9.

16. Kwok EH, Dun NJ. Endomorphins decrease heart rate and blood pressure possibly by activating vagal afferents in anesthetized rats. Brain research. 1998;803(1):204-7.

17. Al Talhi Y, Shirah BH, Altowairqi M, Yousef Y. Laparoscopic cholecystectomy for cholelithiasis in children with sickle cell disease. Clinical Journal of Gastroenterology. 2017:1-7. 